\title{
Characterization of thrombin/factor Xa inhibitors in Rhizoma Chuanxiong through UPLC-MS-based multivariate statistical analysis
}

Yi-Yao Yang ${ }^{1}$, Zhao-Yu Wu ${ }^{1}$, Fang-Bo Xia ${ }^{2}$, Hao Zhang ${ }^{1}$, Xu Wang ${ }^{1}$, Jian-Li Gao ${ }^{3}$, Feng-Qing Yang ${ }^{1 *}$ (i) and Jian-Bo Wan ${ }^{2,4^{*}}$

\begin{abstract}
Background: The dry root and rhizome of Ligusticum chuanxiong Hort., or Chuanxiong, has been used as a bloodactivating and stasis-removing traditional Chinese medicine for 1000 years. Our previous studies have shown the inhibitory activity on platelet and thrombin (THR) of Chuanxiong. THR and factor Xa (FXa) play significant roles in the coagulation cascade and their inhibitors are of valuable in the treatment of thromboembolic diseases. The aim of the present study is to screen THR and FXa inhibitors from Chuanxiong.

Methods: Four extracts [ethyl acetate (EA), butanol (BA) and remained extract (RE) from $75 \%$ ethanol extract, and water extract (WE)] of Chuanxiong were prepared, and their THR/FXa inhibitory activities were assessed in vitro. Following silica-gel column chromatography (SC), the active EA extract and BA extract was further partitioned, respectively. Their active fractions (EA-SC1 to EA-SC5; BA-SC1 to BA-SC5) were obtained and analyzed by LC-MS. After modeling by the principal component analysis (PCA) and orthogonal partial least squares discriminate analysis (OPLSDA), the specific marker compounds were predicted and identified. Their enzyme inhibitory was assessed in vitro and interactions with THR/FXa were investigated by molecular docking analysis.

Results: Chuanxiong EA extract showed strong activity against THR and BA extract was more effective in inhibiting FXa activity, and their fractions exhibited obvious difference in enzyme inhibitory activity. Furthermore, marker compounds $\mathbf{a}-\mathbf{h}$ were predicted by PCA and OPLS-DA, and their chemical structures were identified. Among them, senkyunolide A, Z-ligustilide, ferulic acid and senkyunolide I ( $\mathrm{C}_{50}$ was determined as $0.77 \mathrm{mM}$ ) with potential THR inhibitory activity, as well as isochlorogenic acid A with FXa inhibitory activity were screened out. It was found that the four components could interact with the active site of THR, and the binding energy was lower than $-5 \mathrm{kcal} / \mathrm{mol}$. Isochlorogenic acid A were bound to the active site of FXa, and the binding energy was $-9.39 \mathrm{kcal} / \mathrm{mol}$. The $\mathrm{IC}_{50}$ was determined as $0.56 \mathrm{mM}$.
\end{abstract}

\footnotetext{
*Correspondence: fengqingyang@cqu.edu.cn; jbwan@um.edu.mo

1 School of Chemistry and Chemical Engineering, Chongqing University,

Chongqing 401331, People's Republic of China

${ }^{2}$ State Key Laboratory of Quality Research in Chinese Medicine, Institute

of Chinese Medical Sciences, University of Macau, Taipa, Macao SAR,

People's Republic of China

Full list of author information is available at the end of the article
}

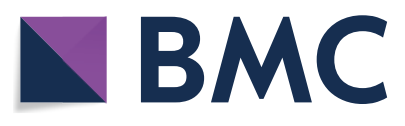

(c) The Author(s) 2020. This article is licensed under a Creative Commons Attribution 4.0 International License, which permits use, sharing, adaptation, distribution and reproduction in any medium or format, as long as you give appropriate credit to the original author(s) and the source, provide a link to the Creative Commons licence, and indicate if changes were made. The images or other third party material in this article are included in the article's Creative Commons licence, unless indicated otherwise in a credit line to the material. If material is not included in the article's Creative Commons licence and your intended use is not permitted by statutory regulation or exceeds the permitted use, you will need to obtain permission directly from the copyright holder. To view a copy of this licence, visit http://creativeco mmons.org/licenses/by/4.0/. The Creative Commons Public Domain Dedication waiver (http://creativecommons.org/publicdomain/ zero/1.0/) applies to the data made available in this article, unless otherwise stated in a credit line to the data. 
Conclusions: THR/FXa inhibitory components in different extracts of Chuanxiong were successfully characterized by the method of enzyme inhibition activity assays with ultra performance liquid chromatography-quadrupole time of flight mass spectrometry-based multivariate statistical analysis.

Keywords: Chuanxiong, Thrombin, Factor Xa, Enzyme inhibitor, Multivariate statistical analysis, Molecular docking

\section{Background}

Thrombin (THR) and factor Xa (FXa) are the members of the serine protease family. As the pivotal enzyme in the blood coagulation processes, FXa act as a catalyst in the THR production by activating prothrombin without existing THR affected [1,2], and THR catalyze the conversion of fibrinogen into insoluble strands of fibrin, as well as stimulate and recruit platelets to the injured site [3]. Due to the importance during blood coagulation cascade, FXa and THR potentially have emerged as attractive targets for new anticoagulants to treat thrombotic diseases. On the other hand, there have been several literature focusing on the study of THR/FXa inhibitory activity of natural products, which include polypeptides [4-7], polyphenols $[8,9]$, saponins [10] and other compounds [11-13]. Rhizoma Chuanxiong, the dried root of Ligusticum chuanxiong Hort. (Umbelliferae), namely Chuanxiong in Chinese, is a famous blood circulation promoting medicine and is one of the clinically used traditional Chinese medicine (TCM) in protecting cardiovascular system. As genuine medicinal material, Chuanxiong is mainly distributed in Sichuan province [14]. Its major chemical components include phthalide lactones, alkaloids, phenolic acids and other constituents [15]. A large body of studies has shown that Chuanxiong possesses multifarious pharmacological effects, including protective effects on neuron [16], heart [17], liver [18] and kidney [19], as well as antioxidation [20, 21], anti-inflammation [22-24], etc. In our previous studies, Chuanxiong extracts had inhibitory effects on platelet aggregation [25] and THR activity [12], while there are few studies on its effects on THR and FXa so far. It is of reasonable to screen THR/FXa inhibitors from Chuanxiong.

Natural products, especially TCMs, are valuable sources of active components for the discovery of novel clinical drug candidates [26-28]. Various techniques to characterize bioactive components from natural products had been reported. The multivariate statistical analysis method can analyze huge amount data generated from liquid chromatography paired with mass spectrometry (LC-MS), and rapidly distinguish the chemical difference among different sample groups [29]. This method had been adopted several times in natural product research for screening of bioactive components [30] or quality control markers [31], studying mechanisms of TCM processing [32] and compatibility [33]. The pharmacological ingredients from the natural products can be efficiently determined by multivariate statistical analysis when combined with bioactivity analysis [34]. Recently, this method has been proved practical and effective in identifying antiplatelet components of edible Citrus limon [35], for the analysis of antidiabetic compounds from TCM formula Ge-Gen-Qin-Lian decoction [36] and for the screening of potential THR/FXa inhibitors from Danshen [37].

In this study, ultra performance liquid chromatography-quadrupole time of flight mass spectrometry (UPLCQTOF-MS) combined with enzyme inhibition activity assays were carried out for analyzing different Chuanxiong fractions. Principal component analysis (PCA) was used to reduce the dimensionality of MS data. Then, orthogonal partial least squares discriminant analysis (OPLS-DA) models were fitted to find out the differential marker compounds based on activity assay results, and their structures were identified. Furthermore, the interaction behaviors between the selected compounds and the enzyme were elucidated by molecular docking analysis. Finally, the enzyme inhibition activities of the marker compounds were evaluated.

\section{Materials and methods \\ Plant material}

Crude drug of Rhizoma Chuanxiong was purchased from Chongqing Xinhu Pharmacy Co., Ltd. (Chongqing, China), and was authenticated by Professor Feng-Qing Yang (School of Chemistry and Chemical Engineering, Chongqing University). The voucher specimen (No. CX2019033001) was deposited at the Pharmaceutical Engineering Laboratory in the School of Chemistry and Chemical Engineering, Chongqing University, Chongqing, China.

\section{Chemicals and reagents}

$Z$-ligustilide, senkyunolide $\mathrm{A}$ and isochlorogenic acid A were purchased from Purechem-standard Co., Ltd. (Chengdu, China). Senkyunolide I, isochlorogenic acid $\mathrm{B}$ and isochlorogenic acid $\mathrm{C}$ were purchased from $\mathrm{PUSH}$ Bio-technology Co., Ltd. (Chengdu, China). Ferulic acid, dopamine hydrochloride and rivaroxaban were obtained from Aladdin Chemistry Co., Ltd. (Shanghai, China). Dimethyl sulphoxide (DMSO) and Tris (hydroxymethyl) aminomethane (Tris) were obtained from Sangon 
Biotech Co., Ltd. (Shanghai, China). Argatroban was purchased from Harvey-bio Co., Ltd. (Beijing, China). FXa and two chromogenic substrates S-2238 and S-2765 were products of Adhoc International Technologies Co., Ltd. (Beijing, China), and THR was bought from SigmaAldrich (St Louis, USA). HPLC-grade acetonitrile and formic acid were obtained from Thermo Fisher Scientific Co., Ltd. (China). HPLC-grade methanol were obtained from Shanghai Tedia Scientific Co., Ltd. (Shanghai, China). All of the experimental water was purified by a water-purification system (ATSelem 1820A, Antesheng Environmental Protection Equipment Co., Ltd., Chongqing, China). Ethanol, butanol (BA), ethyl acetate (EA), petroleum ether $(\mathrm{PE})$, sodium hydroxide $(\mathrm{NaOH})$ and hydrochloric acid $(\mathrm{HCl})$ were of analytical grade and purchased from Chron Chemicals Co., Ltd. (Chengdu, China).

The Tris- $\mathrm{HCl}$ buffer was prepared by adding $1 \mathrm{M} \mathrm{HCl}$ to $10 \mathrm{mM}$ Tris solution ( $\mathrm{pH} 8.0)$. All samples were prepared in Tris- $\mathrm{HCl}$ buffer (10 mM, pH 8.0) with cosolvent DMSO, and diluted to the required concentrations for THR/FXa inhibitory assay, which were stored at $4{ }^{\circ} \mathrm{C}$ and shielded from light before use. The stock solution of THR was prepared in Tris- $\mathrm{HCl}$ buffer $(10 \mathrm{mM}, \mathrm{pH} 8.0)$ with the enzyme activity of $500 \mathrm{U} / \mathrm{mL}$, and stored at $-20^{\circ} \mathrm{C}$. FXa was also dispensed in Tris- $\mathrm{HCl}$ buffer $(10 \mathrm{mM}$, pH 8.0 ) with the enzyme activity of $0.5 \mathrm{IU} / \mathrm{mL}$ and stored at $4{ }^{\circ} \mathrm{C}$.

\section{Preparation of sample extracts}

After comminution, $100 \mathrm{~g}$ of Chuanxiong powder was extracted with $800 \mathrm{~mL} 75 \%$ ethanol $(1: 8, \mathrm{w} / \mathrm{v})$ in a $2 \mathrm{~L}$ glass-stoppered conical flask on water bath at $80{ }^{\circ} \mathrm{C}$ for $1 \mathrm{~h}$; then the extract was filtered, and the residue was collected and extracted with the above process for twice. The three filtrates were combined and concentrated in a rotary evaporator (ZFQ 85 A, Shanghai Medical Instrument Special Factory, Shanghai, China) at $45{ }^{\circ} \mathrm{C}$. After removing ethanol completely, the concentrate were degreased with petroleum ether $(2: 1, \mathrm{v} / \mathrm{v})$, and further subjected to liquid-liquid partitioning to afford EA (2:1, $\mathrm{v} / \mathrm{v}), \mathrm{BA}(1: 1, \mathrm{v} / \mathrm{v})$ soluble extracts as well as the remained extract (RE). After removing the solvent from each solution, the extracts were obtained by reduced pressure distillation and vacuum dry method (DZF-6050, Shanghai Jing Hong Laboratory Instrument Co., Ltd., Shanghai, China). In addition, the residues was extracted twice with $600 \mathrm{~mL}$ water $(1: 6, \mathrm{w} / \mathrm{v})$ on water bath at $80{ }^{\circ} \mathrm{C}$. The two filtrates were combined and evaporated, and further vacuum-dried to obtain the water extract (WE). Total $200 \mathrm{~g}$ Chuanxiong powder was used for extraction.

\section{In vitro THR/FXa inhibitory activity assays}

THR/FXa inhibitory activity assays were performed on an Agilent $71003^{\mathrm{D}}$ capillary electrophoresis (CE) system (Agilent Technologies, Palo Alto, CA, USA), which was equipped with a diode array detector (DAD) and Agilent ChemStation software. All of the experimental procedures were implemented according to literature with minor modifications [38]. The preparation process of immobilized enzyme microreactor (IMER) is described as follows. A new bare fused-silica capillary (i.d. $75 \mu \mathrm{m}$, purchased from Yongnian Ruifeng Chromatographic Device Co., Ltd., Hebei, China) were pretreated with $\mathrm{NaOH}(1 \mathrm{M})$ and deionized water for $15 \mathrm{~min}$ and $10 \mathrm{~min}$, respectively. An automated program was set to prepare the IMER: The dopamine solution $(2 \mathrm{mg} / \mathrm{mL})$ was injected into the capillary with a voltage of $+10 \mathrm{kV}$ for $10 \mathrm{~s}$, stayed for $30 \mathrm{~min}$, and then washed out the free dopamine using running buffer $(10 \mathrm{mM}$ Tris $-\mathrm{HCl}$ buffer solution, $\mathrm{pH}$ 8.0) with a pressure of $-100 \mathrm{mbar}$ for $90 \mathrm{~s}$. Then, the $125 \mathrm{U} / \mathrm{mL}$ THR solution (or $0.5 \mathrm{IU} /$ $\mathrm{mL}$ FXa solution) was introduced into the capillary with a voltage of $+10 \mathrm{kV}$ for $10 \mathrm{~s}$, kept for $30 \mathrm{~min}$; and then flushed by running buffer with a pressure of -100 mbar for $90 \mathrm{~s}$ to wash out free enzyme. The prepared IMER could be immediately used for enzyme inhibitory activity assay. The temperature of the capillary cartridge was maintained at $25^{\circ} \mathrm{C}$ during the $\mathrm{CE}$ analysis. The enzyme inhibitory activity assays were carried out by a reaction that the $2.5 \mathrm{mg} / \mathrm{mL}$ substrate solution (S-2238 for THR assays, S-2765 for FXa assays) with/without inhibitors were injected into the IMER inlet by applying a voltage of $+10 \mathrm{kV}$ for $10 \mathrm{~s}$ and incubated for $60 \mathrm{~s}$ to trigger amidolytic reaction. In order to detect the product p-nitroaniline, the voltage of $+25 \mathrm{kV}$ was applied to separate the reaction mixtures and the detection wavelength was set at $405 \mathrm{~nm}$. The inhibition percentage was calculated by the formula:

$$
\text { Inhibition percentage }(\%)=\left(1-\frac{A_{\text {sample }}}{A_{\text {blank }}}\right) \times 100
$$

where $A_{\text {blank }}$ and $A_{\text {sample }}$ represent the peak area of product yielded by enzymatic reaction of the blank and sample group, respectively. All assays were performed in triplicate and the \% of inhibition was the mean of three observations.

\section{HPLC-DAD analysis}

HPLC analysis was performed on an Agilent 1260 Series liquid chromatography system (Agilent Technologies, Palo Alto, California, USA) which was equipped with a vacuum degasser, a binary pump, an autosampler, and 
a diode array detector (DAD), controlled by an Agilent ChemStation software. An Agilent ZORBAX SB-C18 column $(250 \times 4.6 \mathrm{~mm}$ i.d., $5 \mu \mathrm{m})$ preceded by ZORBAX SB-C18 guard column $(12.5 \times 4.6 \mathrm{~mm}$ i.d., $5 \mu \mathrm{m})$ was used for the separation. The mobile phase consisted of solvent A ( $0.1 \%$ formic acid in water) and solvent B (methanol) with a gradient elution program, which was programmed as follows: $0-20 \mathrm{~min}, 20-35 \% \mathrm{~B} ; 20-32 \mathrm{~min}, 35-43 \% \mathrm{~B}$; 32-42 min, 43-60\% B; 42-47 min, 60-80\% B; 47-52 min, $80 \%$ B; $52-57$ min, $80-20 \%$ B; $57-62 \mathrm{~min}, 20 \%$ B. The solvent flow rate was set at $0.6 \mathrm{~mL} / \mathrm{min}$. The detection wavelength was set at $273 \mathrm{~nm}$, and the column temperature was maintained at $35^{\circ} \mathrm{C}$ and the injection volume was 10 $\mu \mathrm{L}$.

\section{UPLC-QTOF-MS analysis}

A Waters ACQUITY ${ }^{\mathrm{TM}}$ UPLC system coupled with a QTOF SYNAPT G2-Si high-definition mass spectrometer (Waters, Manchester, UK) equipped with an electrospray ionization (ESI) source, was used for the LC-MS analysis and identification. The LC conditions were implemented according to literatures with minor modifications [39]. Chromatographic separations were achieved on an ACQUITY ${ }^{\mathrm{TM}}$ BEH C18 column $(100 \mathrm{~mm} \times 2.1 \mathrm{~mm}$ i.d., $1.7 \mu \mathrm{m})$ at $45{ }^{\circ} \mathrm{C}$. The mobile phase was composed of $0.1 \%$ aqueous formic acid solution (A) and acetonitrile (B) at the flow rate of $0.4 \mathrm{~mL} / \mathrm{min}$. The gradient program were employed as fellows: 0-6 min, 5-50\% B; 6-12 $\mathrm{min}$, $50-60 \%$ B; $12-16 \mathrm{~min}, 60-85 \% \mathrm{~B} ; 16-17 \mathrm{~min}, 85-100 \%$ B; $17-20 \mathrm{~min}, 100 \% \mathrm{~B}$; $20-20.5 \mathrm{~min}, 100-5 \% \mathrm{~B}$; $20.5-$ $23 \mathrm{~min}$, isocratic $5 \% \mathrm{~B}$. The injection volume was $3 \mu \mathrm{L}$. The LC eluent was introduced to a QTOF MS was operated in positive ion mode. The MS parameters were set as follows: capillary voltage, $3.0 \mathrm{kV}$; sample cone voltage, $40 \mathrm{~V}$; source temperature, $150{ }^{\circ} \mathrm{C}$; desolvation temperature, $500^{\circ} \mathrm{C}$; collision energy ramp, 20-40 V. The MS data were acquired by $\mathrm{MS}^{\mathrm{E}}$ scan mode with a mass range from $\mathrm{m} / z 100$ to $\mathrm{m} / z 1500$.

\section{Data processing and multivariate analysis}

The raw LC-MS data of Chuanxiong samples were extracted and processed by Progenesis QI software (Waters Corporation, Milford, MA, USA). After peak recognition, alignment and integration, the intensity of each ion was normalized across samples according to total intensity of each chromatogram. A resultant threedimensional dataset composing of the sample code, peak name $\left(t_{\mathrm{R}}-m / z\right.$ pair $)$ and ion intensity, was generated. After data pre-treatment by mean-centered and paretoscale methods, multivariate statistical analysis, including PCA and OPLS-DA, were conducted by SIMCA-P ${ }^{+} 13.0$ Software (Umetrics, Umeå, Sweden).

\section{In silico molecular docking of THR/FXa and identified potential active compounds}

The purpose of in silico molecular docking study is to validate the binding energy between enzymes and small molecular compounds, which were carried out by Auto Dock 4.2 program (The Scripps Research Institute, La Jolla, CA, USA). The docking operation was performed according to the following steps. Firstly, prepare the file of receptor protein. The X-ray co-crystal structure file of THR-argatroban complex (PDB code $=1 \mathrm{DWC}$ [40]) and FXa-rivaroxaban complex (PDB code $=2 \mathrm{~W} 26$ [41]) were acquired from Protein Data Bank database. Next, the co-crystallized ligand, water were removed, and polar hydrogen atoms were added. Then, the 3D chemical structures of small molecular compounds were drawn by Chem Office and minimized energy with outputting in PDB format. Finally, Lamarckian genetic algorithm (LGA) was employed and the number of GA runs was equal to 50 for finding the most favorable ligand binding orientations. The $2 \mathrm{D}$ interaction diagrams of optimum conformation after docking was generated by Discovery Studio 4.5 (Dassault Systèmes BIOVIA, San Diego, CA, USA) to observe the interaction between molecular compounds and the residues of enzyme.

\section{Results}

\section{Bioactivity-guided fractionation}

The activity evaluation tests against THR/FXa of Chuanxiong different polar extracts (EA, BA, RE and WE extracts, $1.5 \mathrm{mg} / \mathrm{mL}$ ) and each positive control, argatroban and rivaroxaban $(0.5 \mathrm{mg} / \mathrm{mL})$ were employed, and the results were expressed in Fig. 1. The EA extract was more effective in inhibiting THR activity, and the BA extract showed the strongest inhibitory activity toward FXa, which were prioritized for further fractionation.

The EA extract (4.16 g) was applied to normal silica gel column chromatography (SC), and eluted with PE-EA (40:1 to $1: 20, \mathrm{v} / \mathrm{v}$ ) followed by $100 \%$ EA. HPLC analysis was applied to recombine the obtained fractions to give five fractions (EA-SC1 to EA-SC5). The BA extract ( $4.35 \mathrm{~g})$ was eluted with $100 \%$ EA, followed by EA-ME (50:1 to $1: 3, \mathrm{v} / \mathrm{v})$ and $100 \% \mathrm{ME}$ in sequence. HPLC analysis was also applied and five fractions were yielded (BA-SC1 to BA-SC5). THR inhibitory activity of the five EA fractions was measured (Fig. 2a). Fraction EA-SC3 exhibited the strongest inhibitory effect, and fractions EA-SC2, EA-SC4 and EA-SC5 were shown moderate activity, while the inhibition percentage (\%) of THR by EA-SC1 was consistently low compared to the other fractions. As shown in Fig. 2b, the results of FXa inhibitory activity assays among BA fractions indicated that these five fractions could be grouped into two classifications: the most active (BA-SC1 and 


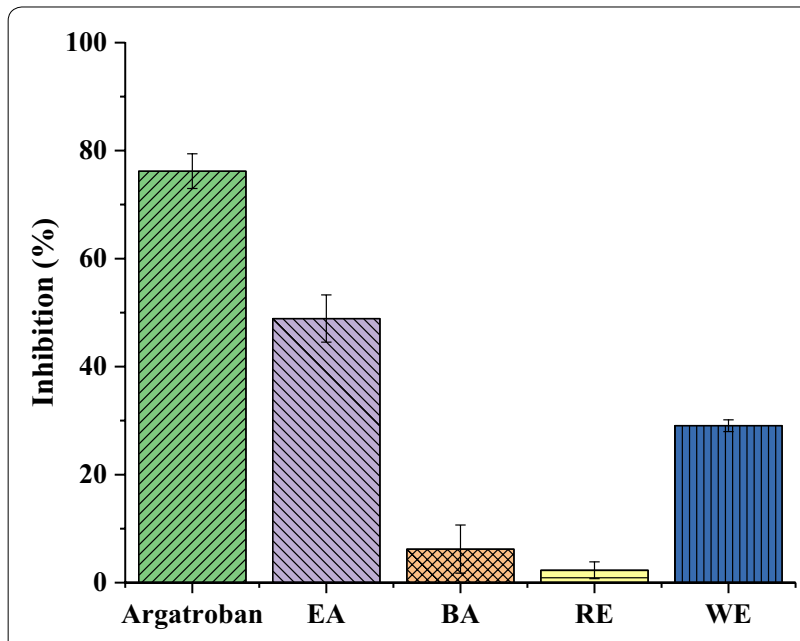

$\mathbf{a}$

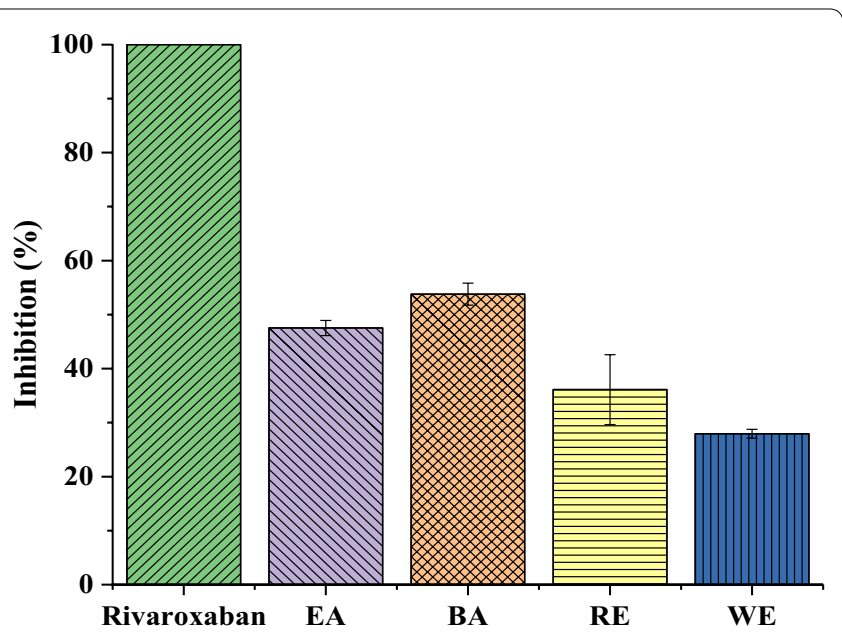

b

Fig. 1 Inhibition percentage (\%) of different fractions of Chuanxiong crude extract on the THR (a) and FXa (b). Data are shown as mean \pm SD from three independent experiments $(n=3)$

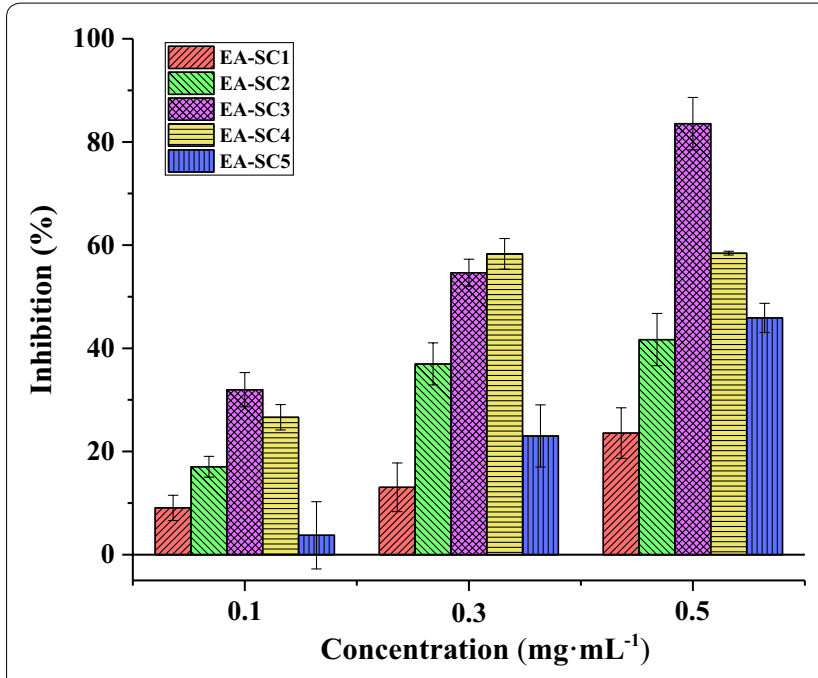

a

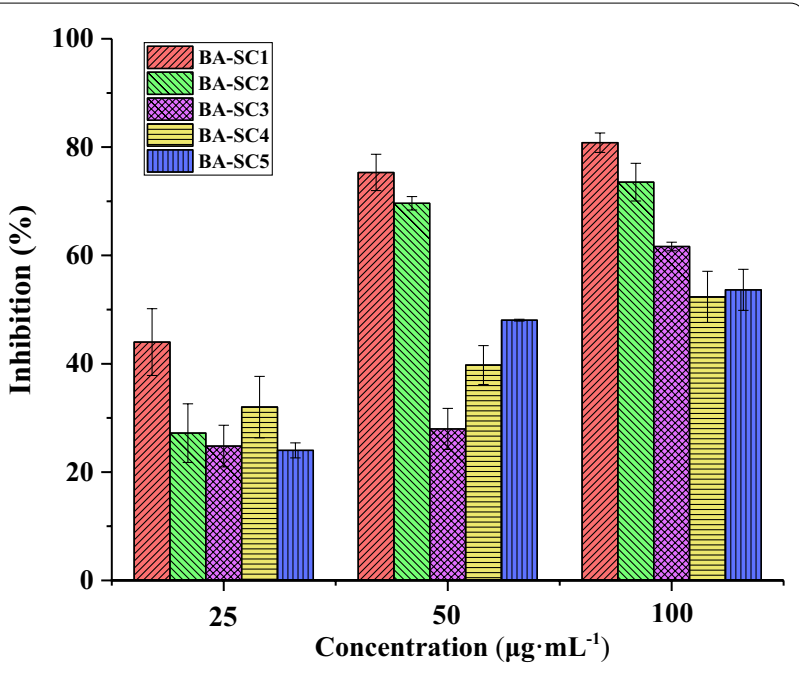

b

Fig. 2 Inhibition percentage (\%) of silica gel fractions of Chuanxiong EA extract on THR (a), and BA extract on FXa (b). Data are shown as mean \pm SD from three independent experiments $(n=3)$

BA-SC2) and moderate active (BA-SC3 to BA-SC5) groups.
Multivariate statistical analysis of active compounds from different fractions

The Chuanxiong fractions, separated by silica column, was subjected to LC-MS analysis in order to conduct an 


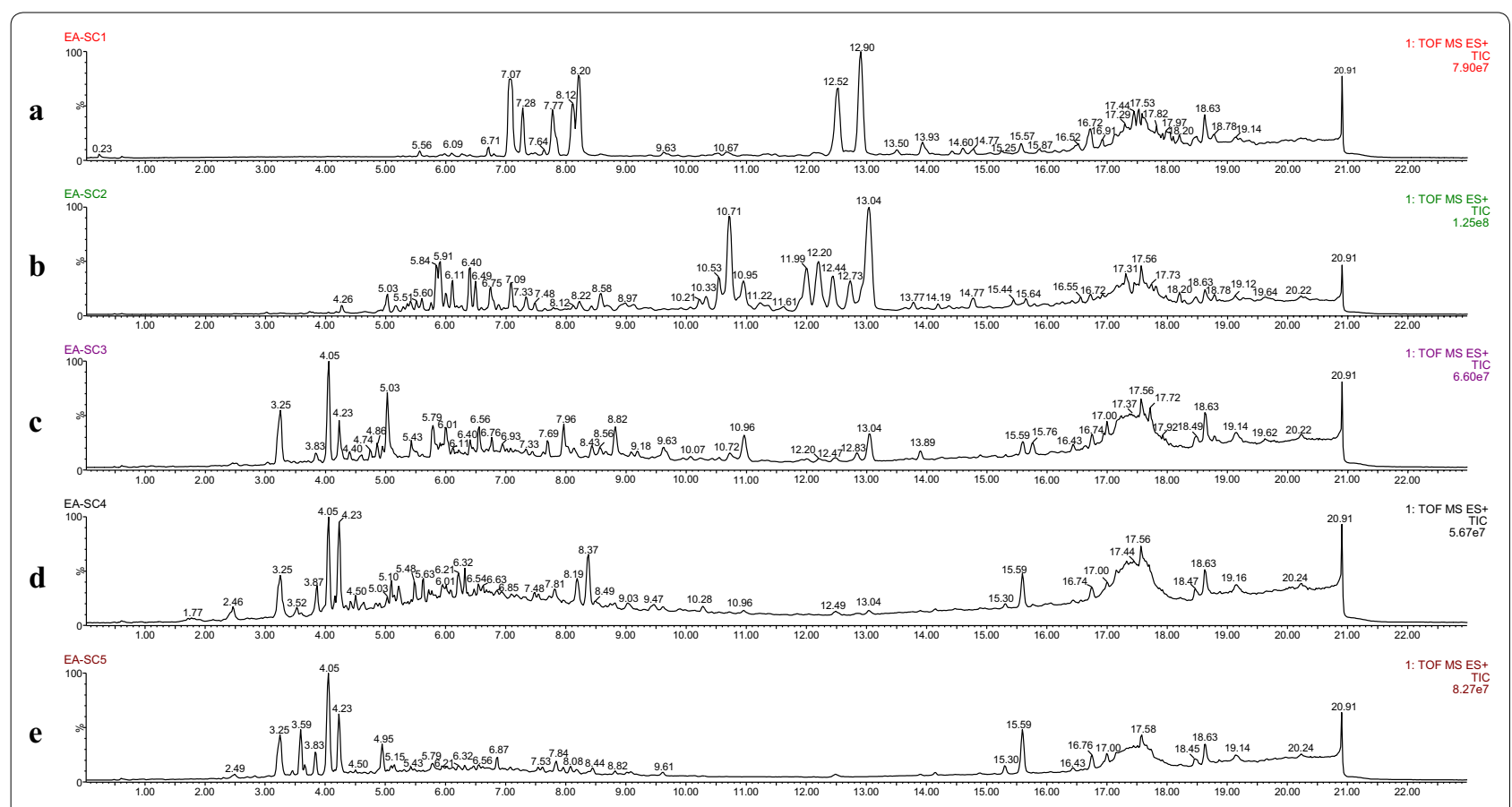

Fig. 3 Total ion chromatograms of five Chuanxiong fractions from EA extract in positive mode. a EA-SC1, b EA-SC2, c EA-SC3, $\mathbf{d}$ EA-SC4 and $\mathbf{e}$ EA-SC5

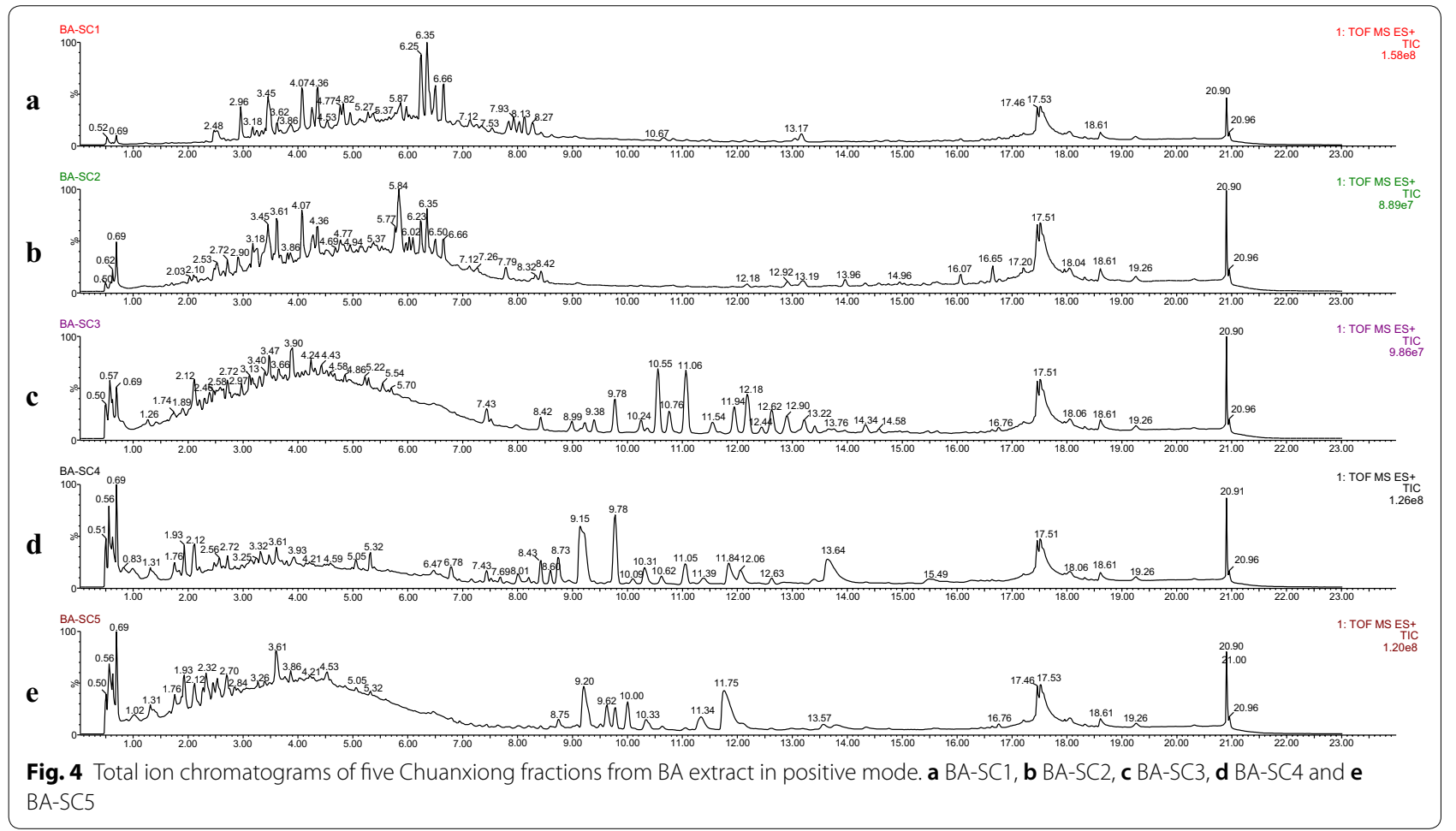

investigation of the differences in their chemical profiles and screening of active marker compounds. The representative total ion chromatographs of five EA fractions
(EA-SC1 to EA-SC5) were illustrated in Fig. 3, and that of five BA fractions (BA-SC1 to BA-SC5) were shown in Fig. 4. This two-processed LC-MS data matrix was 


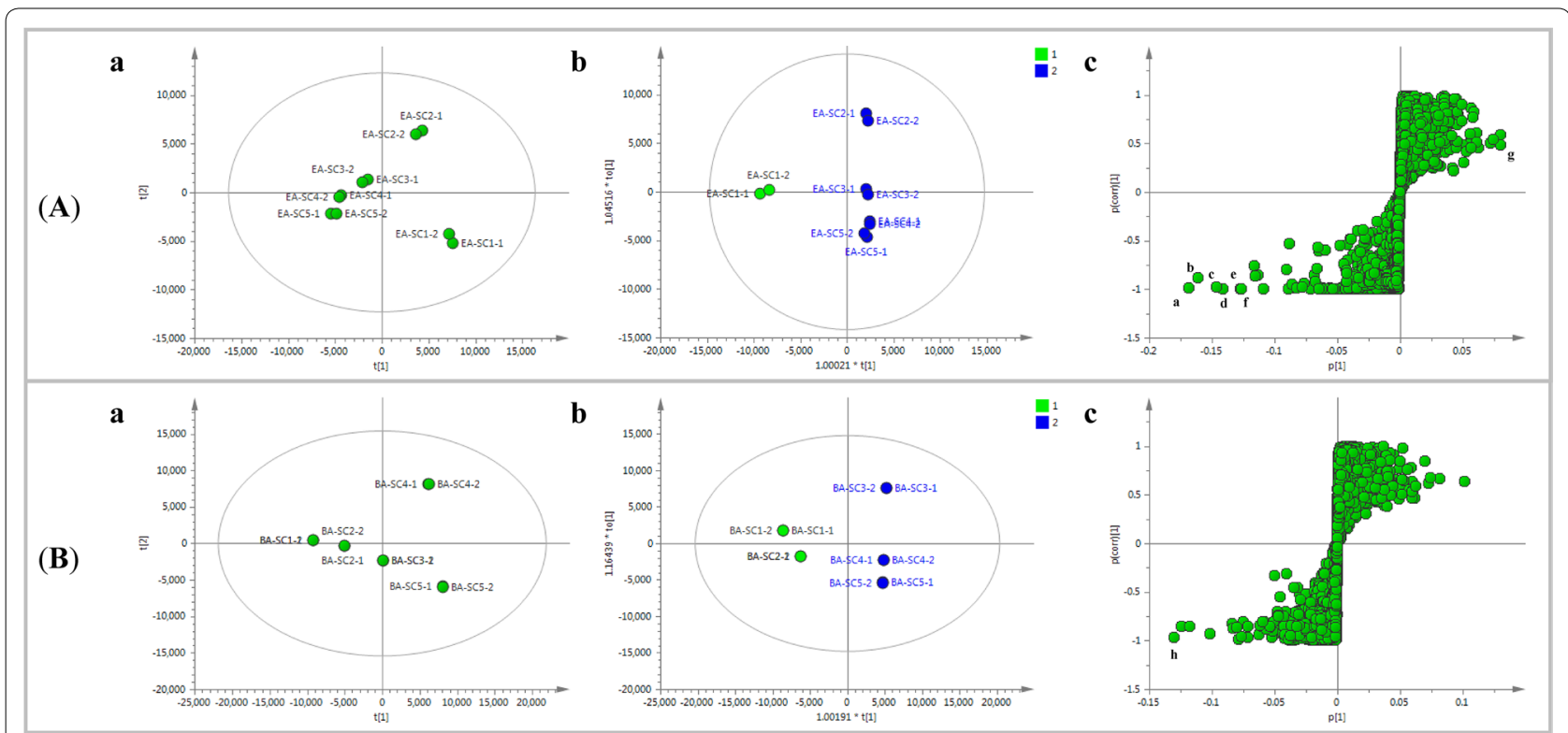

Fig. 5 Chemometric analysis of Chuanxiong EA fractions (A) and BA fractions (B). Score plot from PCA (a), Score plot (b) and S-plot (c) from OPLS-DA, Ellipse: Hotelling's 95\% confidence

generated by Progenesis QI and then was separately imported into SIMCA for unsupervised PCA analysis and supervised OPLS-DA analysis.

To provide visualization of the differences among the Chuanxiong EA fractions, unsupervised PCA analysis was conducted. The score plot (Fig. 5Aa) showed preferably discriminative distribution, and the PCA map could be mainly divided into two clusters: EA-SC1, EA-SC2 to EA-SC5. A correlation was found that this cluster was similar to total ion chromatography of each EA fraction (Fig. 3), which is also consistent with the THR inhibitor activity (Fig. 2). The values of the PCA model fit parameters were 0.782 of $R^{2} X$ (cum) and 0.622 of $Q^{2}$ (cum) and all the samples fell well inside the $95 \%$ confidence interval, indicating a good PCA model. Subsequently, to explore the potential active marker compounds, supervised OPLS-DA analysis was employed to group the Chuanxiong EA fractions in a binary classification as the active and less active groups. The OPLS-DA score plot was presented in Fig. 5Ab, and the five fractions are clearly distinguished and could be classified as active (EA-SC2 to EA-SC5) and less active (EA-SC1). The model fit parameters $R^{2} Y$ (cum) and $Q^{2}$ (cum) were 0.996 and 0.984, respectively, and all the observations fell within the Hotelling T2 (0.95) ellipse, which suggested that the OPLS-DA model $\left(\mathrm{M}_{\mathrm{THR}}\right)$ exhibited good fitting and predictability [42]. In the S-plot (Fig. 5Ac), the ion points far away from the centre (the corner of "S"-shaped curve)

Table 1 Detailed information of eight marker compounds obtained from OPLS-DA S-plot in Chuanxiong fractions

\begin{tabular}{llllll}
\hline Marker compounds & $\mathbf{t}_{\mathbf{R}}(\mathbf{m i n}) \mathbf{- m / z}$ & Ions & VIP & $\begin{array}{l}\text { Formula (neutral } \\
\text { form) }\end{array}$ & Identification \\
\hline $\mathrm{a}^{*}$ & $7.07-193$ & {$[\mathrm{M}+\mathrm{H}]^{+}$} & 16.09 & $\mathrm{C}_{12} \mathrm{H}_{16} \mathrm{O}_{2}$ & Senkyunolide A \\
$\mathrm{b}^{*}$ & $12.90-783$ & {$[2 \mathrm{M}+\mathrm{Na}]^{+}$} & 15.41 & $\mathrm{C}_{24} \mathrm{H}_{28} \mathrm{O}_{4}$ & Ligustilide dimer \\
$\mathrm{c}^{*}$ & $12.52-191$ & {$[\mathrm{M}+\mathrm{H} \text {-ligustilide }]^{+}$} & 13.97 & $\mathrm{C}_{24} \mathrm{H}_{28} \mathrm{O}_{4}$ & Ligustilide dimer \\
$\mathrm{d}^{*}$ & $8.22-191$ & {$[\mathrm{M}+\mathrm{H}]^{+}$} & 13.52 & $\mathrm{C}_{12} \mathrm{H}_{14} \mathrm{O}_{2}$ & Z-Ligustilide \\
$\mathrm{e}^{*}$ & $7.77-191$ & {$[\mathrm{M}+\mathrm{H}]^{+}$} & 12.19 & $\mathrm{C}_{12} \mathrm{H}_{14} \mathrm{O}_{2}$ & Ligustilide isomer \\
$f^{*}$ & $8.12-177$ & {$\left[\mathrm{M}+\mathrm{H}-\mathrm{H}_{2} \mathrm{O}\right]^{+}$} & 12.10 & $\mathrm{C}_{10} \mathrm{H}_{10} \mathrm{O}_{4}$ & Ferulic acid \\
$g^{*}$ & $4.05-207$ & {$\left[\mathrm{M}+\mathrm{H}-\mathrm{H}_{2} \mathrm{O}\right]^{+}$} & 8.00 & $\mathrm{C}_{12} \mathrm{H}_{16} \mathrm{O}_{4}$ & Senkyunolide I \\
$\mathrm{h}^{*}$ & $3.45-499$ & {$\left[\mathrm{M}+\mathrm{H}-\mathrm{H}_{2} \mathrm{O}\right]^{+}$} & 14.17 & $\mathrm{C}_{25} \mathrm{H}_{24} \mathrm{O}_{12}$ & Isochlorogenic acid A \\
\hline
\end{tabular}

* Represents the marker screened from $M_{T H R}$

\# Represents the marker screened from $M_{\mathrm{FXa}}$ 
indicated a larger contribution to the classification of the samples. Marker ions $\mathbf{a}-\mathbf{g}$ were selected with high variable importance in the projection (VIP) scores (VIP >1). The detailed information was listed in Table 1.

The same procedure was employed to discover potential marker compounds from Chuanxiong BA fractions. PCA analysis were employed for investigating the similarity of the constituent profiles of Chuanxiong BA fractions. The values of the PCA model fit parameters were 0.995 for $R^{2} X$ (cum) and 0.985 for $Q^{2}$ (cum) and all the samples fell well inside the $95 \%$ confidence interval. As shown in Fig. 5Ba, in the PCA scores plot of Chuanxiong $\mathrm{BA}$ fractions, $\mathrm{BA}-\mathrm{SC} 1$ and $\mathrm{BA}-\mathrm{SC} 2$ were separated into a cluster distinct from other fractions, which exhibited a trend similar to total ion chromatography of each BA fraction and were observed corresponding with the results of FXa inhibitory activity assays. Then, the OPLSDA model $\left(\mathrm{M}_{\mathrm{FXa}}\right)$ was fitted and showed good fitness and predictability with $Q^{2}(\mathrm{cum})=0.963, R^{2} Y(\mathrm{cum})=0.985$. All the observations fell within the Hotelling T2 (0.95) ellipse. As presented in Fig. 5Bb, the OPLS-DA score plot illustrated that the five fractions could be clearly distinguished and classified as active (BA-SC1, BA-SC2) and less active (BA-SC3 to BA-SC5). In the S-plot (Fig. 5Bc), marker ion $\mathbf{h}$ in the extreme lower left quadrant was selected.

\section{Mass fragmentation analysis of marker compounds}

The identification of chemical markers $\mathbf{a}-\mathbf{h}$ was further investigated, $\mathrm{MS}^{2}$ data verification was conducted with the assist of reported literature [12, 39, 43-46]. Five compounds, including senkyunolide A (a), Z-ligustilide (d), ferulic acid (f), senkyunolide I (g) and isochlorogenic acid $A(\mathbf{h})$, were tentatively identified, and their chemical structures were shown in Fig. 6.

Marker a displayed $[\mathrm{M}+\mathrm{H}]^{+}$ion at $m / z \quad 193$ and $[\mathrm{M}+\mathrm{Na}]^{+}$ion at $m / z 215$. The product ions were obtained at $m / z 175$ for $\left[\mathrm{M}+\mathrm{H}-\mathrm{H}_{2} \mathrm{O}\right]^{+}, m / z 147$ for $\left[\mathrm{M}+\mathrm{H}-\mathrm{H}_{2} \mathrm{O}-\mathrm{CO}\right]^{+}, m / z 137$ for $\left[\mathrm{M}+\mathrm{H}-\mathrm{C}_{4} \mathrm{H}_{8}\right]^{+}, m / z 119$ for $\left[\mathrm{M}+\mathrm{H}-\mathrm{H}_{2} \mathrm{O}-\mathrm{CO}-\mathrm{C}_{2} \mathrm{H}_{4}\right]^{+}$and $m / z 105$ for $[\mathrm{M}+\mathrm{H}-$ $\left.\mathrm{H}_{2} \mathrm{O}-\mathrm{CO}-\mathrm{C}_{3} \mathrm{H}_{6}\right]^{+}$. Therefore, marker a was identified as senkyunolide A $[39,43]$. Marker d yielded $[\mathrm{M}+\mathrm{H}]^{+}$ion at $m / z 191$, which produced fragment ions $\left[\mathrm{M}+\mathrm{H}-\mathrm{H}_{2} \mathrm{O}\right]^{+}$, $\left[\mathrm{M}+\mathrm{H}-\mathrm{H}_{2} \mathrm{O}-\mathrm{CO}\right]^{+}, \quad\left[\mathrm{M}+\mathrm{H}-\mathrm{H}_{2} \mathrm{O}-\mathrm{CO}-\mathrm{C}_{2} \mathrm{H}_{4}\right]^{+}, \quad[\mathrm{M}+\mathrm{H}-$ $\left.\mathrm{H}_{2} \mathrm{O}-\mathrm{CO}-\mathrm{C}_{2} \mathrm{H}_{6}\right]^{+}$and $\left[\mathrm{M}+\mathrm{H}-\mathrm{H}_{2} \mathrm{O}-\mathrm{CO}-\mathrm{C}_{3} \mathrm{H}_{4}\right]^{+}$at $\mathrm{m} / z$ $173,145,117,115,105$. Marker $\mathbf{e}$ and peaks in $7.28 \mathrm{~min}$ and 7.84 min showed same ion fragments as marker $\mathbf{d}$, which were isomers of butylphthalide/E-ligustilide/Zligustilide. According to the peak occurrence sequence and literature [39], marker $\mathbf{d}$ was identified as $Z$-ligustilide. Marker f showed peak of $[\mathrm{M}+\mathrm{H}]^{+}$ion at $m / z 195$ and $[\mathrm{M}+\mathrm{Na}]^{+}$ion at $m / z 217$. The product ions were obtained at $m / z 177$ for $\left[\mathrm{M}+\mathrm{H}-\mathrm{H}_{2} \mathrm{O}\right]^{+}$and $m / z 149$ for

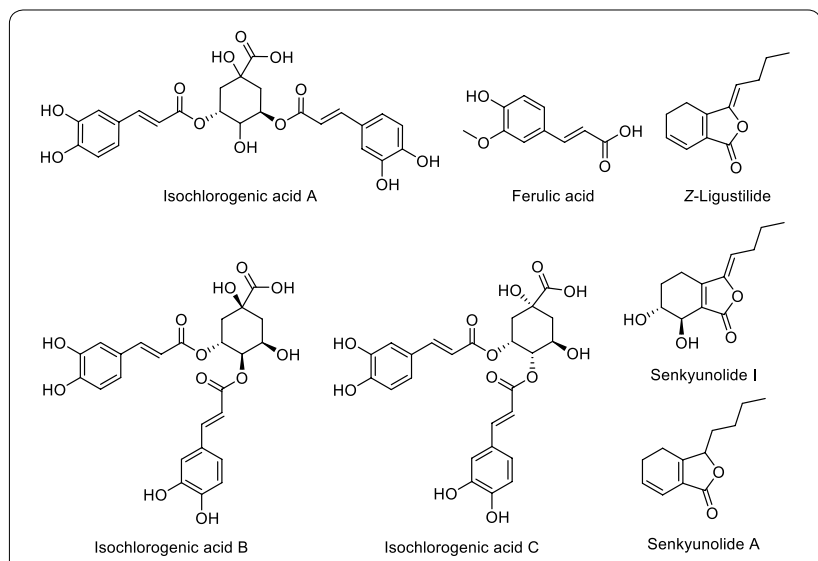

Fig. 6 Chemical structures of the marker compounds prioritized from Chuanxiong extract and the compounds with similar structure

$[\mathrm{M}+\mathrm{H}-\mathrm{HCOOH}]^{+}$. Therefore, marker $\mathbf{f}$ was identified as ferulic acid [43-45]. Marker $\mathbf{g}$ gave $[\mathrm{M}+\mathrm{Na}]^{+}$ion at $\mathrm{m} / z$ 247. Ions at $\mathrm{m} / z 207, \mathrm{~m} / z 189$ and $\mathrm{m} / z 161$ were also detected, which were formed by sequential losses of $\mathrm{H}_{2} \mathrm{O}$, $\mathrm{H}_{2} \mathrm{O}$ and $\mathrm{CO}$ from $[\mathrm{M}+\mathrm{H}]^{+}$ion. Therefore, marker $\mathbf{g}$ was identified as senkyunolide I [39, 44].

Marker $\mathbf{h}$ exhibited typical fragment ion at $m / z 499$ by the loss of the group of $\mathrm{H}_{2} \mathrm{O}$ from $[\mathrm{M}+\mathrm{H}]^{+}$ion at $\mathrm{m} / z$ 517. The [caffeoyl $+\mathrm{H}]^{+}$ion at $m / z 163$ were also found, which were deduced to be formed by the loss of caffeoyl and quinic acid from $[\mathrm{M}+\mathrm{H}]^{+}$ion. In order to further confirming its structure, the MS data in the negative ion mode was recorded. The typical and major fragment ions were generated by the loss of caffeoyl and $\mathrm{H}_{2} \mathrm{O}$ from $[\mathrm{M}-\mathrm{H}]^{-}$ion $(m / z 515)$, such as $[\mathrm{M}-\mathrm{H} \text {-caffeoyl }]^{-} m / z 353$, [M-H-caffeoyl- $\left.\mathrm{H}_{2} \mathrm{O}\right]^{-} \mathrm{m} / z \quad 335$ and [M-H-2caffeoyl$\left.\mathrm{H}_{2} \mathrm{O}\right]^{-} m / z 191$. With the reference compounds and literature [12, 46], marker $\mathbf{h}$ was identified as isochlorogenic acid $\mathrm{A}$.

\section{Molecular docking analysis of THR/FXa and identified potential active compounds}

Molecular docking can be used to study the binding mechanism of compounds interacting with the active site of proteins. The docking energy and binding residues of four markers (from Chuanxiong EA fractions) with THR active site were gathered in Table 2 . The active sites of THR have four binding pockets [47]: S1 pocket (specificity pocket), S2 pocket (proximal pocket), S3 pocket, and S4 pocket (aryl binding pocket). For the docking with THR (Fig. 7), it was observed that four marker compounds could insert into the catalytic active pocket of THR like original ligand argatroban via multifarious interactions such as hydrogen bond and van der Waals, etc. The main part of argatroban interacted with 
Table 2 Docking results and residues interactions of four inhibitors screened from Chuanxiong EA fractions and argatroban with THR

\begin{tabular}{|c|c|c|c|c|}
\hline Compounds & $\begin{array}{l}\text { Docking } \\
\text { energy } \\
\left(\mathrm{kcal} \cdot \mathrm{mol}^{-1}\right)\end{array}$ & Hydrogen bond & Van der Waals & Electrostatic interaction and other \\
\hline Senkyunolide A & -6.48 & - & $\begin{array}{l}\text { GLY226, ASP189, TYR225, GLU217, GLY216, GLY219, } \\
\text { CYS220, CYS191, SER195, SER214, TRP215, PHE227 }\end{array}$ & VAL213, ALA190, TYR228 \\
\hline Z-ligustilide & -7.13 & GLY226, PHE227 & $\begin{array}{l}\text { TYR225, GLY216, GLU217, ASP221, GLY219, CYS191, } \\
\text { GLU192, ASP194, VAL213, TYR228, SER214, TRP215, } \\
\text { CYS220 }\end{array}$ & ASP189, LYS224, ARG221A, ALA190 \\
\hline Ferulic acid & -5.3 & $\begin{array}{l}\text { SER195, GLY193, } \\
\text { ASP189, } \\
\text { PHE227, } \\
\text { GLY226 }\end{array}$ & $\begin{array}{l}\text { TYR225, GLY216, GLY219, CYS191, ASP194, HIS57, GLU192, } \\
\text { VAL213, SER214, TRP215 }\end{array}$ & TYR228, ALA190, CYS220 \\
\hline Senkyunolide I & -6.99 & SER195, GLY226 & $\begin{array}{l}\text { PHE227, TYR225, GLY216, ASP189, GLU217, ASP221, } \\
\text { GLY219, ARG221A, CYS191, GLU192, GLY193, ASP194, } \\
\text { HIS57, VAL213, TRP215 }\end{array}$ & ALA190, CYS220, SER214, LYS224 \\
\hline Argatroban & -8.90 & $\begin{array}{l}\text { GLY219, GLY216, } \\
\text { HIS57, SER195, } \\
\text { GLY193, } \\
\text { ALA190 }\end{array}$ & $\begin{array}{l}\text { ASP221, CYS220, CYS191, ASP194, GLU217, TRP215, } \\
\text { GLY226, SER214, GLU192, LEU99, CYS42, LEU41, TYR225 }\end{array}$ & TRP60D, ASP189, TYR60A, LYS60F \\
\hline
\end{tabular}

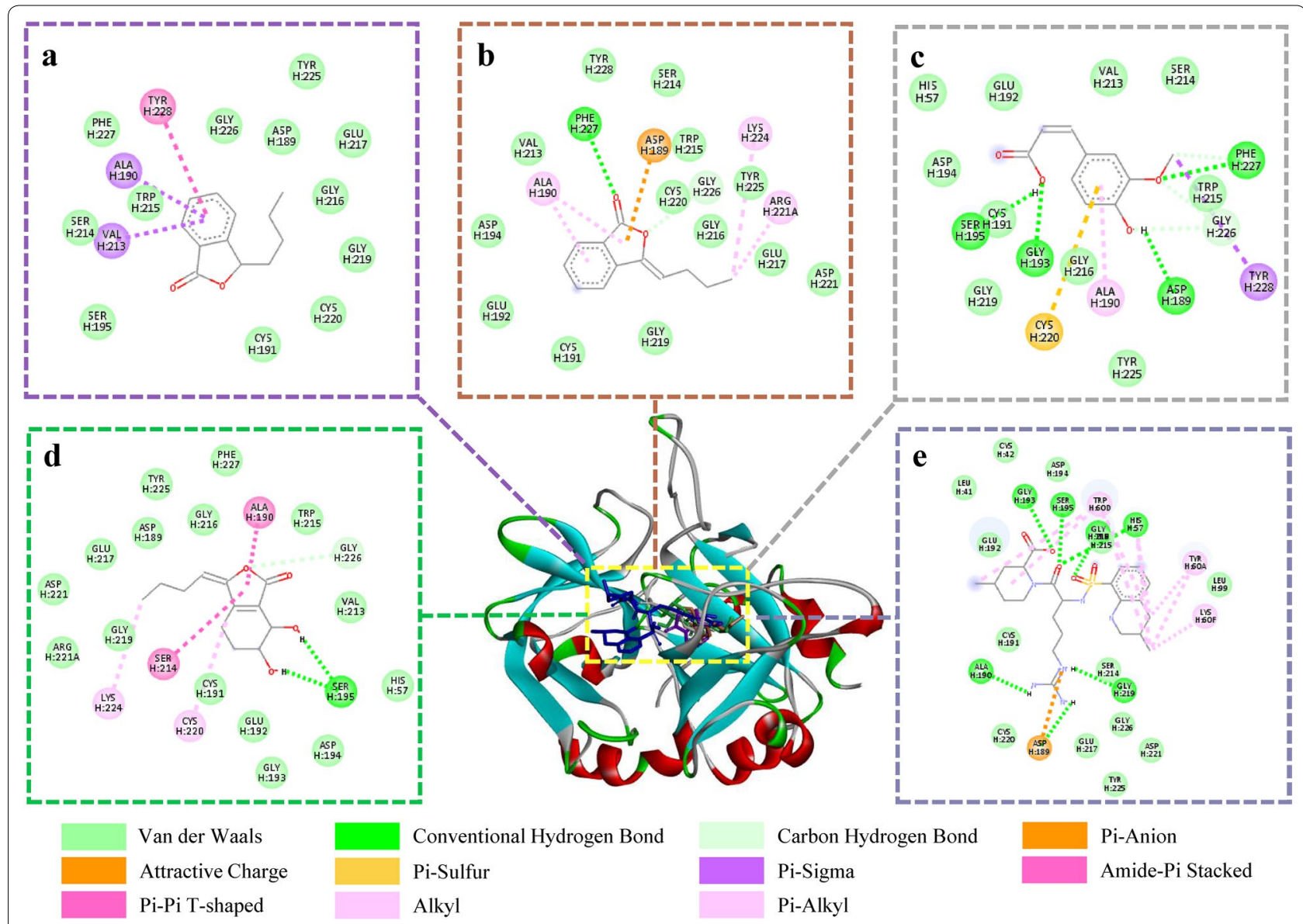

Fig. 7 Binding mode and interaction between four screened inhibitors and the THR catalytic site. a Senkyunolide A, b Z-Ligustilide, c Ferulic acid, $\mathbf{d}$ Senkyunolide l, e Argatroban 
S2 pocket, and its guanido group partially blocked S1 pocket. Senkyunolide A, Z-ligustilide, ferulic acid and senkyunolide I were mainly located at $\mathrm{S} 1$ pocket by interacting with ASP189, ALA190, CYS191, CYS220, GLY216, GLY219, GLY226, PHE227, TRP215 and so on. Binding energy of them were $-6.48,-7.13,-5.3$ and $-6.99 \mathrm{kcal} /$ mol, respectively.

Molecular docking with FXa was also carried out. The docking energy and binding residues of isochlorogenic acid A (from Chuanxiong BA fractions) and its isomers with FXa active site were shown in Table 3. FXa also has four binding pockets, S1 pocket to S4 pocket [47]. Isochlorogenic acid $\mathrm{A}, \mathrm{B}$ and $\mathrm{C}$ had similar binding portion with rivaroxaban bound to FXa (Fig. 8). The interactions were diverse including hydrogen bond and van der Waals, etc. When docked with FXa, rivaroxaban is mainly located in S4 pocket, and its chlorothiophene amide part interacted with amino acids between S1 and $\mathrm{S} 2$ pockets. The caffeinyl group in 5 position of quinine ring of isochlorogenic acid A and C occupied S4 pocket. Another caffeinyl group combined with $\mathrm{S} 1$ pocket and penetrated into its bottom through hydrogen bonding with ASP189. The quinine ring of isochlorogenic acid B mainly inserted into S2 pocket, and the caffeinyl groups interacted with the amino acids around $\mathrm{S} 1$ pocket. The binding energy of isochlorogenic acid $\mathrm{A}, \mathrm{B}$ and $\mathrm{C}$ were $-9.39,-8.67$ and $-9.71 \mathrm{kcal} / \mathrm{mol}$, respectively.

\section{In vitro activity assessment of the predicted compounds}

The reference compounds, which were based on the four identified markers (senkyunolide A, Z-ligustilide, ferulic acid and senkyunolide I) screened from Chuanxiong EA fractions, were further examined for their inhibitory effects on the THR activity. Among them, senkyunolide I strongly inhibited THR activity with an $\mathrm{IC}_{50}$ value of
$0.77 \mathrm{mM}$ (Fig. 9). Senkyunolide A and $Z$-ligustilide on the inhibiting of THR activity were weaker than that of senkyunolide I with \% inhibition around $40 \%$ at a relatively high concentration $(0.5 \mathrm{mM})$, while ferulic acid did not show inhibitory effect on the THR activity under such concentration. The inhibition results were summarized in Table 4. The marker compound screened from Chuanxiong $\mathrm{BA}$ fractions, isochlorogenic acid $\mathrm{A}$, and its isomers (isochlorogenic acid B and C) were further examined for their potential inhibitory effects on the FXa activity. From the results shown in Fig. 9, these compounds possessed FXa inhibitory effects in a dose-dependent behavior, and $\mathrm{IC}_{50}$ value were $0.56,0.77$ and $0.61 \mathrm{mM}$, respectively.

\section{Discussion}

Chuanxiong EA extract has the strongest inhibitory activity against THR among four different polar extracts, and its fractions (EA-SC1 to EA-SC5) exhibited activity difference. In order to compare the chemical profiles of five fractions, multivariate statistical analysis with two fraction classes were used. Based on OPLS-DA model, markers a-g were the main components that contribute to the difference of composition and enzyme inhibitory activity among fractions. Four of them were identified as senkyunolide A (a), Z-ligustilide (d), ferulic acid (f) and senkyunolide I (g). FXa inhibitory activity assessment results demonstrated a different tendency, in which Chuanxiong BA extracts showed the highest enzyme inhibitory activity. An FXa inhibitor isochlorogenic acid A (h) was screened using the same way. Chuanxiong extracts has the different effective position toward THR and FXa, which give a hint that THR inhibitor might mainly exist in low polar phthalides and FXa inhibitors could be found in high polar phenolic acids.

Table 3 Docking results and residues interactions of three isochlorogenic acids and rivaroxaban with FXa

\begin{tabular}{|c|c|c|c|c|}
\hline Compounds & 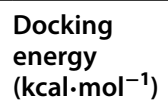 & Hydrogen bond & Van der Waals & $\begin{array}{l}\text { Electrostatic interaction } \\
\text { and other }\end{array}$ \\
\hline Isochlorogenic acid A & -9.39 & $\begin{array}{l}\text { GLN192, GLY193, THR98, GLU97, } \\
\text { TYR99, SER214, ASP189 }\end{array}$ & $\begin{array}{l}\text { GLN61, MET180, ILE175, PHE174, } \\
\text { HIS57, SER195, GLY216, VAL213, } \\
\text { ILE227, TYR228, GLY226, TYR225, } \\
\text { GLY219, CYS191, ASP194 }\end{array}$ & TRP215, ALA190, CYS220 \\
\hline Isochlorogenic acid B & -8.67 & $\begin{array}{l}\text { GLN192, GLN61, TRP215, SER214, } \\
\text { GLY216, GLU147, GLY226 }\end{array}$ & $\begin{array}{l}\text { HIS57, SER195, GLY193, ASP189, } \\
\text { ILE227, ARG143, LYS148, GLY219, } \\
\text { TYR99 }\end{array}$ & $\begin{array}{l}\text { TYR228, VAL213, ALA190, CYS191, } \\
\text { CYS220 }\end{array}$ \\
\hline Isochlorogenic acid C & -9.71 & $\begin{array}{l}\text { GLY216, SER195, HIS57, ASP189, } \\
\text { GLY219, THR98, TYR99 }\end{array}$ & $\begin{array}{l}\text { GLN192, VAL213, ILE227, TYR228, } \\
\text { GLY226, TYR225, CYS220, } \\
\text { GLU217, ALA221, GLU97, PHE174, } \\
\text { ILE175, MET180 }\end{array}$ & TRP215, ALA190, SER214, CYS191 \\
\hline Rivaroxaban & -10.19 & GLY216, THR98, ILE175 & $\begin{array}{l}\text { GLU97, PHE174, GLN192, GLY219, } \\
\text { CYS191, ALA190, SER195, SER214, } \\
\text { MET180, THR177 }\end{array}$ & CYS220, TRP215, TYR99, VAL213 \\
\hline
\end{tabular}




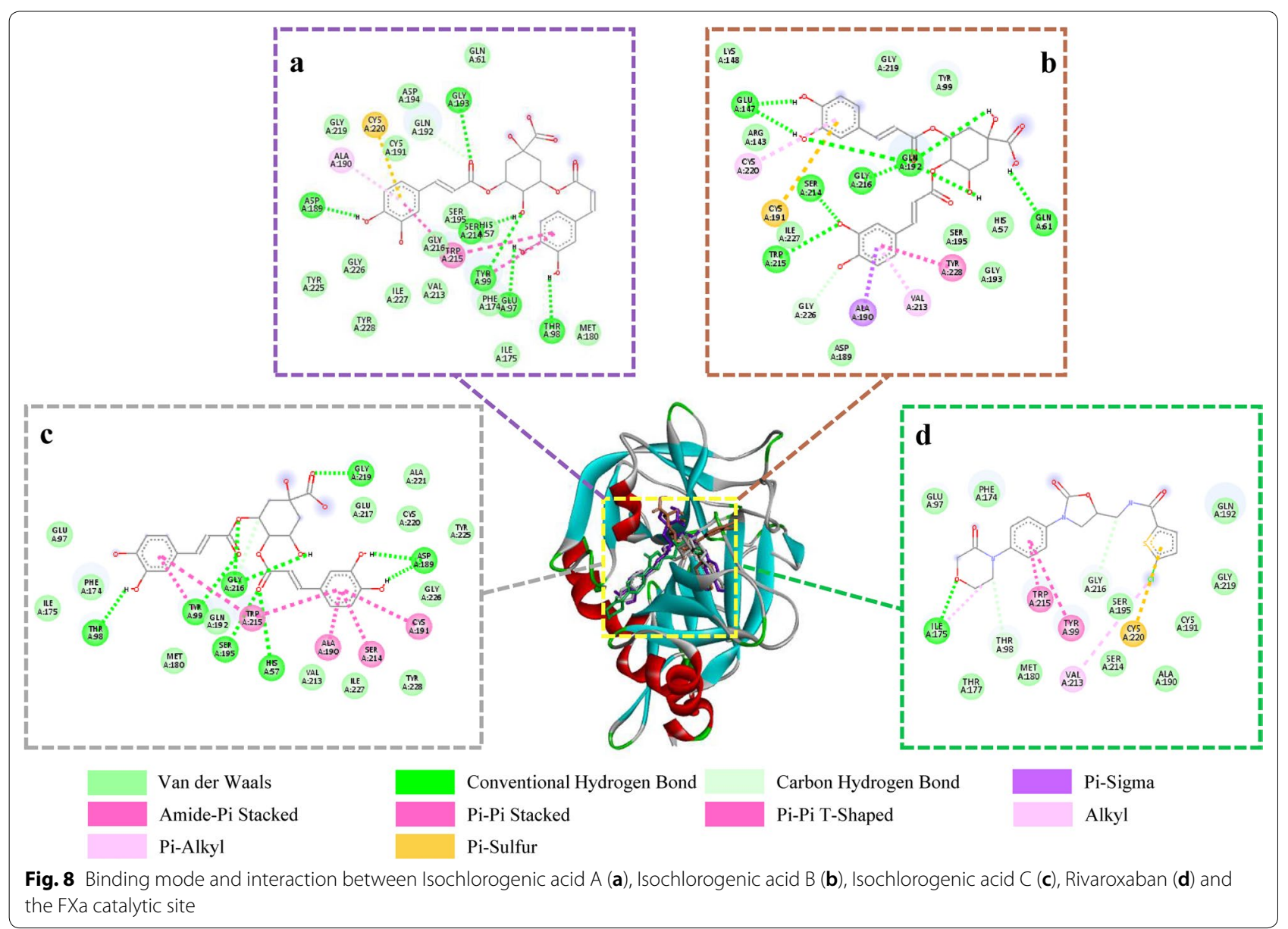

Molecular docking can be used to study the binding mechanism of compounds interact with protein such as characterizing the binding site and evaluating the strength of interaction [48]. It was demonstrated that the four screened marker compounds from Chuanxiong EA extracts were bound to the THR active sites and the binding energies were below $-5 \mathrm{kcal} / \mathrm{mol}$. Generally, the region with binding energy lower than $-5.0 \mathrm{kcal} /$ mol could be considered the "Potential Targets" [49]. Therefore, senkyunolide A, Z-ligustilide, ferulic acid and senkyunolide I were potential THR inhibitors. Their inhibitory effects on THR activity were examined. Among them, senkyunolide I had the strongest activity, and senkyunolide $\mathrm{A}$ and $Z$-ligustilide showed moderate activity, while ferulic acid exhibited no effect which could explain the low binding energy of ferulic acid that is close to $-5 \mathrm{kcal} / \mathrm{mol}$. In addition, the $\mathrm{IC}_{50}$ of senkyunolide I differed from the report [12], which may be due to the different experimental methods and conditions (such as concentrations of substrate and enzyme activity). Likewise, the interaction between isochlorogenic acid A, B and $\mathrm{C}$ and FXa were investigated. The result of binding energy of isochlorogenic acid $\mathrm{A}$ and $\mathrm{C}(<-9 \mathrm{kcal} / \mathrm{mol})$ is better than isochlorogenic acid $\mathrm{B}(-8.67 \mathrm{kcal} / \mathrm{mol})$. Isochlorogenic acid $\mathrm{A}$ and $\mathrm{C}$ interacted with the $\mathrm{S} 1$ and $\mathrm{S} 4$ pocket of $\mathrm{FXa}$, and isochlorogenic acid $\mathrm{B}$ could interact with $\mathrm{S} 1$ and $\mathrm{S} 2$ pocket. It has been reported that $\mathrm{S} 1$ and $\mathrm{S} 4$ pockets are commonly used to predict high-affinity FXa inhibitors [50]. Therefore, these three molecules are potential inhibitors of FXa. The results of inhibitory effects on the FXa activity indicated that isochlorogenic acid $A$ and $C$ had the lower $\mathrm{IC}_{50}$ value. A possible explanation is that they have similar binding site and energy.

Senkyunolide I, which has been screened out as a THR inhibitor from Chuanxiong ethanol extract by ultrafiltration in our previous study [12], was also screened out in this study along with senkyunolide A and Z-ligustilide. Among the three compounds, senkyunolide I had the strongest inhibitory activity, probably because of its two phenolic hydroxyl groups have hydrogen bonding with SER195 that belongs to the THR catalytic triad. In addition, one of the FXa inhibitors found in this study is isochlorogenic acid $\mathrm{C}$, which was also discovered as a THR inhibitor in our previous 

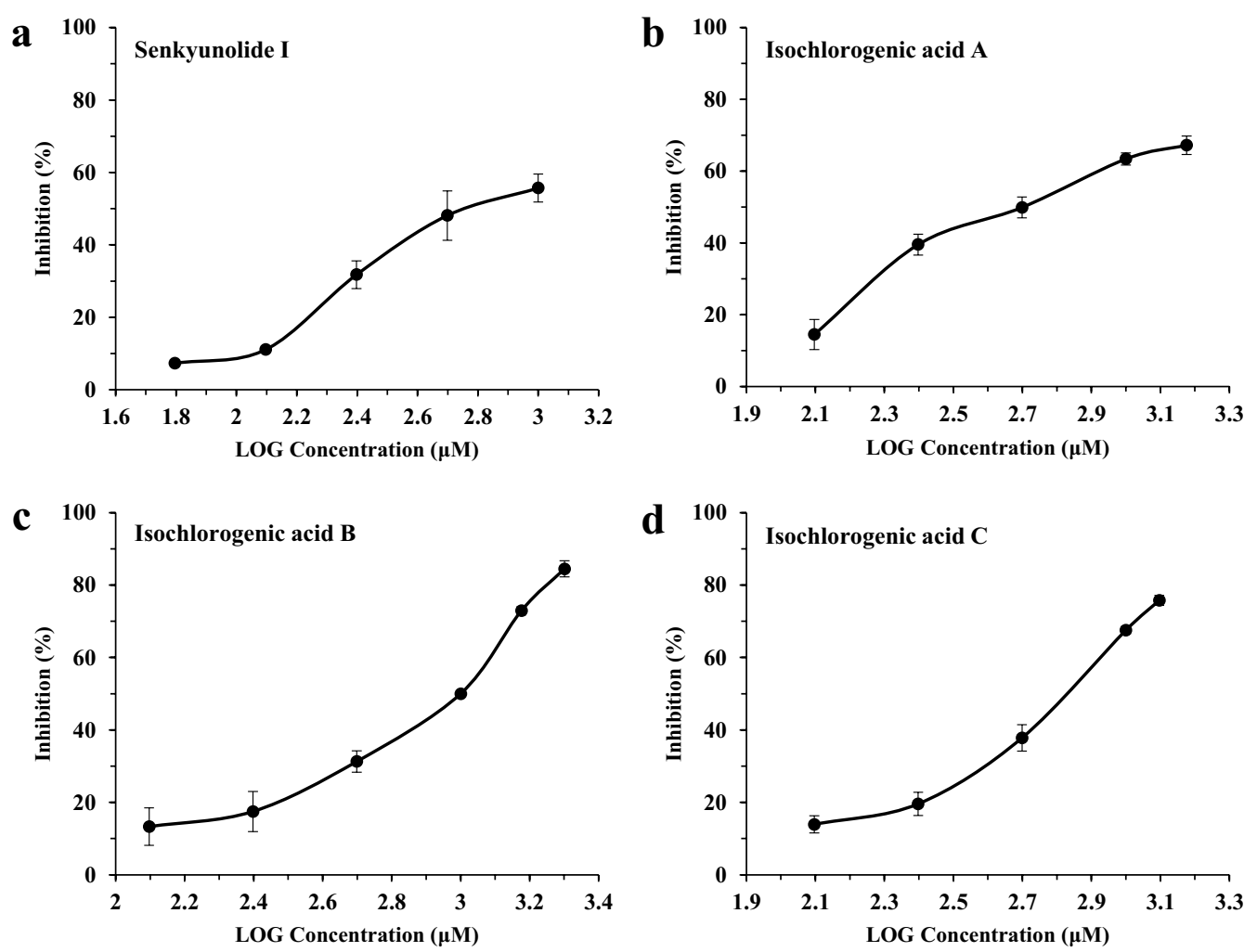

Fig. 9 Inhibition effect of Senkyunolide I (a), Isochlorogenic acid A (b), Isochlorogenic acid B (c) and Isochlorogenic acid C (d) on enzyme. a THR, b-d FXa. Data are shown as mean \pm SD from three independent experiments $(n=3)$

Table 4 Inhibition effect of Senkyunolide A, Z-ligustilide and Ferulic acid on THR

\begin{tabular}{llc}
\hline Compounds & Concentration $(\mathbf{m M})$ & $\begin{array}{l}\text { Inhibition } \\
\text { percentage (\%) }\end{array}$ \\
\hline Senkyunolide A & 0.5 & $41.90 \pm 1.84$ \\
& 0.25 & $31.99 \pm 2.58$ \\
Z-ligustilide & 0.125 & $28.51 \pm 2.42$ \\
& 0.5 & $36.92 \pm 2.37$ \\
Ferulic acid & 0.25 & $26.04 \pm 1.84$ \\
& 0.125 & $25.52 \pm 1.17$ \\
& 0.5 & $-7.72 \pm 1.91$ \\
& 0.25 & $1.01 \pm 3.59$ \\
& 0.125 & $1.01 \pm 4.17$
\end{tabular}

study [12]. The explanation may be that its larger molecular structure and more hydroxyl groups make it able to bind to the residues in the active pocket of the center of THR/FXa pocket. Therefore, it could be a dual-enzyme inhibitor.

\section{Conclusion}

Rhizoma Chuanxiong has been used for thousands of years in TCM, and is well-known for its properties of "HuoXueHuaYu" (activating blood circulation to remove blood stasis). It has various kinds of biological activities such as vasodilation, antiinflammatory, antioxidation, antiproliferation, etc. Through the combination method of LC-MS analysis, THR/FXa activity assessment and multivariate statistical analysis, this study predicted and identified four marker compounds (senkyunolide A, Z-ligustilide, ferulic acid and senkyunolide I) with potential THR inhibitory activity from Chuanxiong EA fractions, and one marker compound isochlorogenic acid A, with potential FXa inhibitory activity from Chuanxiong BA fractions. Docking results showed that five screened compounds could insert into the catalytic active site of enzyme, and the binding energy was lower than $-5 \mathrm{kcal} / \mathrm{mol}$. The $\mathrm{IC}_{50}$ of senkyunolide I and isochlorogenic acid A was 0.77 and $0.56 \mathrm{mM}$, respectively. In addition, two other FXa inhibitors, isochlorogenic acid $\mathrm{B}$ and isochlorogenic acid $\mathrm{C}$, with similar structure to isochlorogenic acid $\mathrm{A}$, were also found, with $\mathrm{IC}_{50}$ value of 0.77 and $0.61 \mathrm{mM}$, respectively. These results proved that the proposed 
method could effectively characterize the THR/FXa inhibitors in complex mixtures, which not only complemented the anticoagulant mechanism of Rhizoma Chuanxiong, but also provided a clue for the discovery of new active THR and/or FXa inhibitors.

\begin{abstract}
Abbreviations
BA: Butanol; CE: Capillary electrophoresis; DAD: Diode array detector; DMSO: Dimethyl sulphoxide; EA: Ethyl acetate; El: Electrostatic interaction; ESI-MS: Electrospray ionization-mass spectrometer; FXa: Factor Xa; IMER: Immobilized enzyme microreactor; LC-MS: Liquid chromatography paired with mass spectrometry; LGA: Lamarckian genetic algorithm; OPLS-DA: Orthogonal partial least squares discriminant analysis; PCA: Principal component analysis; PE: Petroleum ether; UPLC-QTOF-MS: Ultra performance liquid chromatography-quadrupole-time of flight-mass spectrometer; RE: Remained extract; SC: Silica gel column chromatography; TCM: Traditional Chinese medicine; THR: Thrombin; Tris: Tris (hydroxymethyl) aminomethane; VIP: Variable importance in the projection; WE: Water extract.
\end{abstract}

\section{Acknowledgements}

No applicable.

\section{Authors' contributions}

YYY and FQY design the study. YYY conducted the study and drafted the manuscript. JBW and FQY supervised the study and revised the manuscript. ZYW, FBX, HZ, XW and JG provided the technical support and advices for the study. All authors read and approved the final manuscript.

\section{Funding}

This work was supported by Opening Project of Zhejiang Provincial Preponderant and Characteristic Subject of Key University (Traditional Chinese Pharmacology), Zhejiang Chinese Medical University (No. ZYAOX2018015), and was sponsored by Natural Science Foundation of Chongqing, China (cstc2019jcyj-msxmX0074) and the Research Committee of the University of Macau (MYRG2017-00035-ICMS) and the Science and Technology Development Fund, Macau SAR (File no. 065/2018/A2).

\section{Availability of data and materials}

The research data generated from this study is included within the article.

\section{Ethics approval and consent to participate}

Not applicable.

\section{Consent for publication}

Not applicable.

\section{Competing interests}

The authors declare that they have no competing interests.

\section{Author details}

${ }^{1}$ School of Chemistry and Chemical Engineering, Chongqing University, Chongqing 401331, People's Republic of China. ${ }^{2}$ State Key Laboratory of Quality Research in Chinese Medicine, Institute of Chinese Medical Sciences, University of Macau, Taipa, Macao SAR, People's Republic of China. ${ }^{3}$ Academy of Chinese Medical Sciences, Zhejiang Chinese Medical University, Hangzhou 310053, Zhejiang, People's Republic of China. ${ }^{4}$ College of Pharmacy, Chengdu University of Traditional Chinese Medicine, Chengdu, Sichuan, China.

Received: 11 July 2020 Accepted: 24 August 2020

Published online: 31 August 2020

\section{References}

1. Leadley RJ. Coagulation factor Xa inhibition: biological background and rationale. Curr Top Med Chem. 2001;1(2):151-9.
2. Tan YF, Wang Q, Gong JW, Zhang XG, Li YH, Zhang JQ, et al. Bioassaydirected fractionation of a blood coagulation factor $X a$ inhibitor, betulinic acid from Lycopus lucidus. Open Chem. 2018;16(1):170-5.

3. Coughlin SR. Thrombin signalling and protease-activated receptors Nature. 2000:407(6801):258-64.

4. Salzet M, Chopin V, Baert JL, Matias I, Malecha J. Theromin, a novel leech thrombin inhibitor. J Biol Chem. 2000;275(40):30774-80.

5. Arocas V, Zingali RB, Guillin MC, Bon C, Jandrot-Perrus M. Bothrojaracin: a potent two-site-directed thrombin inhibitor. Biochemistry. 1996;35(28):9083-9.

6. Faria F, Kelen EMA, Sampaio CAM, Bon C, Duval N, Chudzinski-Tavassi AM. A new factor Xa inhibitor (lefaxin) from the Haementeria depressa leech. Thromb Haemostasis. 1999;82(5):1469-73.

7. Mao SS, Huang J, Welebob C, Neeper MP, Garsky VM, Shafer JA, et al. Identification and characterization of variants of tick anticoagulant peptide with increased inhibitory potency toward human factor Xa. Biochemistry. 1995;34(15):5098-103.

8. Li QQ, Yang YX, Qv JW, Hu G, Hu YJ, Xia ZN, et al. Investigation of interactions between thrombin and ten phenolic compounds by affinity capillary electrophoresis and molecular docking. J Anal Methods Chem. 2018;2018:4707609.

9. Bijak M, Ponczek MB, Nowak P. Polyphenol compounds belonging to flavonoids inhibit activity of coagulation factor X. Int J Biol Macromol. 2014:65:129-35.

10. Dahmer T, Berger M, Barlette AG, Reck J, Segalin J, Verza S, et al. Antithrombotic effect of chikusetsusaponin IVa isolated from llex paraguariensis (Maté). J Med Food. 2012;15(12):1073-80.

11. Ku SK, Bae JS. Antithrombotic activities of sulforaphane via inhibiting platelet aggregation and Flla/FXa. Arch Pharm Res. 2014;37(11):1454-63.

12. Zhang $Q$, Yang YX, Li SY, Wang YL, Yang FQ, Chen H, et al. An ultrafiltration and high performance liquid chromatography coupled with diode array detector and mass spectrometry approach for screening and characterizing thrombin inhibitors from Rhizoma Chuanxiong. J Chromatogr B. 2017;1061:421-9.

13. Song HP, Wu SQ, Hao HP, Chen J, Lu J, Xu XJ, et al. A chemical familybased strategy for uncovering hidden bioactive molecules and multicomponent interactions in herbal medicines. Sci Rep. 2016;6:23840.

14. Shi XJ, Chen L, Peng C. Comparative study of chemical composition of chuanxiong from different commodities specifications. J Sichuan Tradit Chin Med. 2011;29(4):58-61.

15. Li WX, Tang YP, Chen YY, Duan JA. Advances in the chemical analysis and biological activities of Chuanxiong. Molecules. 2012;17:10614-51.

16. Wang M, Yao MJ, Liu JX, Takagi N, Yang B, Zhang M, et al. Ligusticum chuanxiong exerts neuroprotection by promoting adult neurogenesis and inhibiting inflammation in the hippocampus of ME cerebral ischemia rats. J Ethnopharmacol. 2020;249:112385.

17. Wang G, Dai GL, Song J, Zhu MM, Liu Y, Hou XF, et al. Lactone component from Ligusticum chuanxiong alleviates myocardial ischemia injury through inhibiting autophagy. Front Pharmacol. 2018;9:301.

18. Zhang $X$, Feng ZM, Yang YN, Jiang JS, Zhang PC. Bioactive butylphthalide derivatives from Ligusticum chuanxiong. Bioorg Chem. 2019;84:505-10.

19. Yang WJ, Li YR, Gao H, Wu XY, Wang XL, Wang XN, et al. Protective effect of the ethanol extract from Ligusticum chuanxiong rhizome against streptozotocin-induced diabetic nephropathy in mice. J Ethnopharmacol. 2018;227:166-75.

20. Ramalingam M, Park YK. Free radical scavenging activities of Cnidium officinale Makino and Ligusticum chuanxiong Hort. methanolic extracts. Pharmacogn Mag. 2010;6(24):323-30.

21. Jeong JB, Ju SY, Park JH, Lee JR, Yun KW, Kwon ST, et al. Antioxidant activity in essential oils of Cnidium officinale makino and Ligusticum chuanxiong Hort and their inhibitory effects on DNA damage and apoptosis induced by ultraviolet B in mammalian cell. Cancer Epidemiol. 2009;33(1):41-6.

22. Or TC, Yang CL, Law AH, Li JC, Lau AS. Isolation and identification of anti-inflammatory constituents from Ligusticum chuanxiong and their underlying mechanisms of action on microglia. Neuropharmacology. 2011;60(6):823-31.

23. Wei ZQ, Dong DJ, Guan LP, Wang YF, Huang JH, Wen XH. A metabolic exploration of the protective effect of Ligusticum wallichii on IL-1 betainjured mouse chondrocytes. Chin Med. 2020;15(1):12. 
24. Zhang C, Guan DG, Jiang M, Liang C, Li L, Zhao N, et al. Efficacy of leflunomide combined with ligustrazine in the treatment of rheumatoid arthritis: prediction with network pharmacology and validation in a clinical trial. Chin Med. 2019;14(1):26.

25. Chen C, Wang FQ, Xiao W, Xia ZN, Hu G, Wan JB, et al. Effect on platelet aggregation activity: extracts from 31 Traditional Chinese Medicines with the property of activating blood and resolving stasis. J Tradit Chin Med. 2017;37(1):64-75.

26. Wang JF, Wei DQ, Chou KC. Drug candidates from traditional chinese medicines. Curr Top Med Chem. 2008;8(18):1656-65.

27. Wang JF, Wei DQ. Role of structural bioinformatics and traditional Chinese medicine databases in pharmacogenomics. Pharmacogenomics. 2009;10(8):1213-5.

28. Tang MP, Wang ZX, Zhou Y, Xu WJ, Li ST, Wang LY, et al. A novel drug candidate for Alzheimer's disease treatment: gx-50 derived from Zanthoxylum bungeanum. J Alzheimers Dis. 2013;34(1):203-13.

29. Li ZY, Du Y, Yuan YL, Zhang XJ, Wang ZT, Tian X. Integrated quality evaluation strategy for multi-species resourced herb medicine of Qinjiao by metabolomics analysis and genetic comparation. Chin Med. 2020;15(1):16

30. Chan KM, Yue GGL, Li P, Wong ECW, Lee JKM, Kennelly EJ, et al. Screening and analysis of potential anti-tumor components from the stipe of Ganoderma sinense using high-performance liquid chromatography/time-offlight mass spectrometry with multivariate statistical tool. J Chromatogr A. 2017;1487:162-7.

31. Liang WY, Chen WJ, Wu LF, Li S, Qi Q, Cui YP, et al. Quality evaluation and chemical markers screening of Salvia miltiorrhiza Bge. (Danshen) based on HPLC fingerprints and HPLC-MS ${ }^{n}$ coupled with chemometrics. Molecules. 2017;22(3):478

32. Ding MY, Jiang Y, Yu XA, Zhang D, Li J, Wang H, et al. Screening of combinatorial quality markers for natural products by metabolomics coupled with chemometrics. A case study on Pollen Typhae. Front Pharmacol. 2018;9:691.

33. Wang MR, Li YY, Huang Y, Tian Y, Xu FG, Zhang ZJ. Chemomic and chemometric approach based on ultra-fast liquid chromatography with ion trap time-of-flight mass spectrometry to reveal the difference in the chemical composition between Da-Cheng-Qi decoction and its three constitutional herbal medicines. J Sep Sci. 2014;37(9-10):1148-54.

34. Kellogg JJ, Todd DA, Egan JM, Raja HA, Oberlies NH, Kvalheim OM, et al. Biochemometrics for natural products research: comparison of data analysis approaches and application to identification of bioactive compounds. J Nat Prod. 2016;79(2):376-86

35. Zhang Q, Tan CN, Cai L, Xia FB, Gao D, Yang FQ, et al. Characterization of active antiplatelet chemical compositions of edible Citrus limon through ultra-performance liquid chromatography single quadrupole mass spectrometry-based chemometrics. Food Funct. 2018;9(5):2762-73.

36. Yan Y, Du CH, Li ZY, Zhang M, Li J, Jia JP, et al. Comparing the antidiabetic effects and chemical profiles of raw and fermented Chinese Ge-Gen-QinLian decoction by integrating untargeted metabolomics and targeted analysis. Chin Med. 2018;13(1):54.

37. Yang YY, Wu ZY, Zhang H, Yin SJ, Xia FB, Zhang Q, et al. LC-MS-based multivariate statistical analysis for the screening of potential thrombin/factor Xa inhibitors from Radix Salvia Miltiorrhiza. Chin Med. 2020;15(1):38.
38. Wu ZY, Zhang H, Yang YY, Yang FQ. An online dual-enzyme co-immobilized microreactor based on capillary electrophoresis for enzyme kinetics assays and screening of dual-target inhibitors against thrombin and factor Xa. J Chromatogr A. 2020;1619:460948.

39. Zhang QQ, Wang ML, Wang Q, Zhang HZ, Zhang ZX, Yu HH, et al. Characterization of the potential new phthalides in Ligusticum chuanxiong Hort. using ultra-performance liquid chromatography coupled with quadrupole time of flight tandem mass spectrometry. J Sep Sci. 2017:40(10):2123-30.

40. Banner DW, Hadváry P. Crystallographic analysis at 3.0-Å resolution of the binding to human thrombin of four active site-directed inhibitors. J Biol Chem. 1991;266(30):20085-93.

41. Roehrig S, Straub A, Pohlmann J, Lampe T, Pernerstorfer J, Schlemmer $\mathrm{KH}$, et al. Discovery of the novel antithrombotic agent 5-Chloro- $\mathrm{N}-(\{(5 \mathrm{~S})-$ 2-oxo-3-[4-(3-oxomorpholin-4-yl)phenyl]-1,3-oxazolidin-5-yl\}methyl) thiophene-2-carboxamide (BAY 59-7939): an oral, direct factor Xa inhibitor. J Med Chem. 2005;48(19):5900-8.

42. Eriksson L, Jaworska J, Worth AP, Cronin MTD, McDowell RM, Gramatica P. Methods for reliability and uncertainty assessment and for applicability evaluations of classification- and regression-based QSARs. Environ Health Perspect. 2003;111(10):1361-75.

43. Hu Y. Study on the separation, extraction, and structual identification of the chemical composition from Ligusticum chuanxiong Hort. Changchun Normal University. 2013

44. Zhang XL, Liu LF, Zhu LY, et al. A high performance liquid chromatography fingerprinting and ultra high performance liquid chromatography coupled with quadrupole time-of-flight mass spectrometry chemical profiling approach to rapidly find characteristic chemical markers for quality evaluation of dispensing granules, a case study on Chuanxiong Rhizoma. J Pharmaceut Biomed Anal. 2014;88:391-400.

45. Pu ZH, Meng CW, Zhou YX, Peng C, Du JC, Xiong L. Chemical constituents from Ligusticum chuanxiong. Zhong Yao Cai. 2016;39(11):2529-31.

46. Huang QM, Xu SY, Tai YN, Shen SJ, Guo HT, Huang MQ. Simultaneous determination of fifteen components in Jinmu Ganmao tablets by UPLCMS/MS. Chin J Pharm Anal. 2017;37(8):1453-60.

47. Nar $\mathrm{H}$. The role of structural information in the discovery of direct thrombin and factor Xa inhibitors. Trends Pharmacol Sci. 2012;33(5):279-88.

48. Mozzicafreddo M, Cuccioloni M, Eleuteri AM, Fioretti E, Angeletti M. Flavonoids inhibit the amidolytic activity of human thrombin. Biochimie. 2006;88(9):1297-306.

49. Lu J, Song HP, Li P, Zhou P, Dong X, Chen J. Screening of direct thrombin inhibitors from Radix Salviae Miltiorrhizae by a peak fractionation approach. J Pharm Biomed Anal. 2015;109:85-90.

50. Vaz RJ, McLean LR, Pelton JT. Evaluation of proposed modes of binding of (2S)-2-[4-[[(3S)-1-acetimidoyl3-pyrrolidinyl]oxy]phenyl]-3-(7-amidino2-naphthyl)propanoic acid hydrochloride and some analogs to factor Xa using a comparative molecular field analysis. J Comp Aid Mol. 1998;12(2):99-110.

\section{Publisher's Note}

Springer Nature remains neutral with regard to jurisdictional claims in published maps and institutional affiliations.
Ready to submit your research? Choose BMC and benefit from:

- fast, convenient online submission

- thorough peer review by experienced researchers in your field

- rapid publication on acceptance

- support for research data, including large and complex data types

- gold Open Access which fosters wider collaboration and increased citations

- maximum visibility for your research: over $100 \mathrm{M}$ website views per year

At BMC, research is always in progress.

Learn more biomedcentral.com/submissions 